\title{
GOVERNING TRANSNATIONAL INNOVATION POLICY: THE CASE OF THE BLUE BIOECONOMY IN THE MEDITERRANEAN
}

\section{David Fernández"; Lourdes Reig; Martin Alba; Xavier Díaz}

"Centre for Agro-Food Economics and Deveopment (CREDA, Castelldefels,
david.fernandez.guerrero@upc.edu)

Recent developments in regional innovation policy have challenged the assumptions of smart specialisation strategies (S3). Initially aimed at governing innovation for growth, S3 need to tackle societal, sustainable development challenges. To this end, reformed S3 approaches are being implemented. The present study sets out to propose an extension of one such approach, the shared agendas led by the Catalan government. Through a literature review, the study will propose an extended shared agendas governance model -the governance arrangements set in place to coordinate innovation projects towards a common goal- suitable to the blue bioeconomy, that is those economic activities related to the living resources at sea. In addition, the shared agendas will be extended to coordinate innovation projects across regions and countries in the Mediterranean. The resulting governance model will be useful to initiatives coordinating food-related innovation, transnationally ${ }^{3}$.

Keywords: Blue bioeconomy, innovation policy, sustainable development challenges, transnational governance

\section{Introduction and goals}

In recent years, scholars have increasingly become interested in the directionality of smart specialisation strategies (S3), and innovation policy more generally (Fitjar et al., 2019; Mazzucato, 2016; Molas-Gallart et al., 2020). While traditional frames to justify innovation support measures emphasised the relevance of innovation as a driver of economic growth, scholars increasingly pay attention to the social and environmental consequences of innovation (Schot \& Steinmueller, 2018).

S3 policies are thus expected to be more responsible (Fitjar et al., 2019), i.e. they are expected to anticipate their positive -and negative-impacts while including the interests and needs of a wide range of stakeholders in their formulation and implementation. Complementarily, they are expected to reflect on their impact and be responsive to emerging needs during implementation. In response to such needs, innovation policies have been redesigned to align innovation towards societal goals and sustainable development. Approaches such as transformative innovation policy (Molas-Gallart et al., 2020; Schot \& Steinmueller, 2018) and the more recent shared agendas (Ariño \& Fernández, 2021; Marinelli et al., 2021), exemplify the efforts to promote innovation as a tool to tackle complex, sustainable development challenges.

The present study focuses on one of the revised S3 policy approaches, the shared agendas. The approach will be revised with an eye on promoting a governance model suitable to sustainable development challenges in the blue bioeconomy, across the Mediterranean, focusing on the following question:

- How can the shared agendas governance model be extended to promote innovation cooperation on the sustainable development in the blue bioeconomy, across the Mediterranean?

\section{Methodology}

The present study is based on a literature review combining the following sources:

- Peer-reviewed articles and grey literature, covering recent developments in S3 strategies, and innovation policy more generally (Fitjar et al., 2019; Molas-Gallart et al., 2020; Schot \& Steinmueller, 2018).

- Grey literature, articles discussing the shared agendas approach to regional innovation policy (Ariño \& Fernández, 2021; Marinelli et al., 2021).

- Grey literature, reports covering the latest developments in the blue bioeconomy, in the Mediterranean (EUMOFA, 2020; Francocci et al., 2019).

- Peer-reviewed articles and grey literature, covering recent developments in challenges related to the blue bioeconomy (Miedzinski et al., 2019; Wayman \& Niemann, 2021).

\footnotetext{
${ }^{3}$ This study has been possible thanks to the support from the economic promotion area of the Catalan government, as part of the Interreg MED project Blue Bio Med.
} 
This combination of sources stems from the emerging nature of the field. Whereas some recent debates in S3 strategies and innovation policy are already part of the debate held in academic journals, others have only recently been proposed. Additionally, some sources are directed primarily at a practitioner audience articles on the shared agendas, and the blue bioeconomy in the Mediterranean-. The authors held meetings with key informants from the economic promotion area of Catalan Government, who suggested literature on the shared agendas approach. The authors carried out the literature review in preparation for multistakeholder workshops exploring how can innovation cooperation help tackling sustainable development challenges through innovation, as part of the Interreg MED project Blue Bio Med ${ }^{4}$.

\section{Results}

Approaches revising S3 innovation policy can be analysed based on the relevance they assign to innovators proposing alternative solutions to sustainable development challenges. This trait features prominently in transformative innovation policy (Molas-Gallart et al., 2020; Schot \& Steinmueller, 2018). This literature proposes spaces where alternative solutions to sustainable development challenges can be upscaled, overcoming the constraints set to innovations not relying upon dominant technologies and rules.

Inspired by transformative innovation policy and the multi-level perspective, the shared agendas approach (Ariño \& Fernández, 2021; Marinelli et al., 2021) proposes a methodology that policymakers can apply when coordinating innovation projects around sustainable development challenges. Concretely, a narrative should be built, aligning a coalition of societal stakeholders around a shared vision. To be able to tackle that challenge, however, innovators proposing alternative solutions have to contribute actively. This is because sustainable development challenges are typically based on complex, systemic problems, where innovations based on dominant technologies do not suffice. A regional governance model for multistakeholder coalitions (Fernández \& Romagosa, 2020) was proposed, based on:

- A strategic committee performing advocacy group and strategic leadership functions. A technical office with functions such as coordinating and supporting actions towards the shared future vision; designing and managing a monitoring system focused on learning and adaptation; providing equal opportunities for participation; influencing political agendas.

- Working groups of stakeholders aligned around alternative solutions. Having a largely selfgoverned nature, their number and internal composition varies with stakeholder priorities. They add flexibility and experimentation capacity to the governance model.

However, shared agendas depart, like transformative innovation policy (Molas-Gallart et al., 2020; Schot $\&$ Steinmueller, 2018), from the assumption that the dominant regime conditioning the innovations pursued by society -with its technologies and rules- is present at different territorial scales, and global trends such as climate change can open windows of opportunity to alternative innovations. Hence, the shared governance model could be suited to transnational multi-stakeholder coalitions. A transnational strategic committee and technical office could be created and working groups could be organised around specific projects. Depending on stakeholder priorities, the working groups could be based on regional, national or thematic nodes, and they could be regularly reshuffled to support experimentation with alternative innovations.

The extended shared agendas governance model could be applied to different challenges in the blue bioeconomy. Emerging activities such as Integrated multi-trophic Aquaculture (IMTA) or micro and macro-algae farming and exploitation require technological innovation, but also improvements in for instance funding to de-risk investments, specialised skills, market development, or the social perception of new products (EUMOFA, 2020; Francocci et al., 2019). Thus, these are challenges that cannot be solely tackled through technological innovation. Rather, they require changes in policies and social practices, as well as business models. Furthermore, coordinated policy changes across countries and regions in the Mediterranean might be required.

Similarly, the model could be applied to challenges affecting the preservation of marine living resources, such as tackling marine plastic waste. Macro-plastic waste has been related to deaths by suffocation; the ingestion of micro-plastic debris is related to a decrease in the quality of life, survivability and reproducibility of marine animals. Nano-plastic, in addition, might be able to penetrate biological membranes, disrupting the functioning of cells. Its effects might reverberate across the marine ecosystem, with changes in algae photosynthesis or the metabolism and hormonal signalling of fish (Mendenhall, 2018; Wayman \& Niemann, 2021). In the Mediterranean yearly intake of 230,000 tonnes of marine plastic debris has been estimated (Boucher \& Billard, 2020). A broad range of solutions has been proposed to tackle the challenge, including new consumption patterns reducing the use of plastic, enhanced waste management

\footnotetext{
${ }^{4}$ https://blue-bio-med.interreg-med.eu/
} 
and recycling systems, or new ways of recovering and recycling plastic waste at sea (Miedzinski et al., 2019). Hence, together with new technologies, changes in social practices might be required concerning the use and disposal of plastic, and new business models should be developed regarding its recycling. Coordinated policy action across the Mediterranean could accelerate such changes.

\section{Conclusions}

New types of innovation policy are required to tackle challenges related to sustainable development in blue bioeconomy activities such as IMTA and micro/macro-algae farming exploration; as well as threats to sustainable development in the blue bioeconomy such as marine plastic debris. These policies should be able to combine directionality, i.e. an emphasis in aligning innovation projects towards tackling the challenge, with room for experimentation with alternative types of innovations. Owing to the multi-faceted nature of the challenges, one-sided solutions do not suffice.

The present study suggests that one of such approaches to innovation policy - the shared agendas- can contribute to tackling these challenges. Because societal stakeholders build a common narrative around the goal of tackling the challenge, a shared vision aligns their efforts, while also accommodating the inclusion of alternative solutions to the challenge. Meanwhile, the working groups included in the governance model enable experimenting with alternative solutions; receiving support in this task from the technical office. The technical office, furthermore, should animate the participation of alternative types of actors. Largely regional originally, the shared agendas governance model can be readily extended to transnational, Mediterranean-wide challenges like those of the blue bioeconomy, promoting learning and coordination across networks of innovators, transnationally. An example of the governance model for the plastics challenge is proposed in graphic 1 .

Further research is required before fine-tunning the shared agendas governance model, however, its design makes it a promising option for coordinating food-related transnational innovation efforts.

Graphic 2. Example of a governance model, challenge of marine plastic debris in the Mediterranean

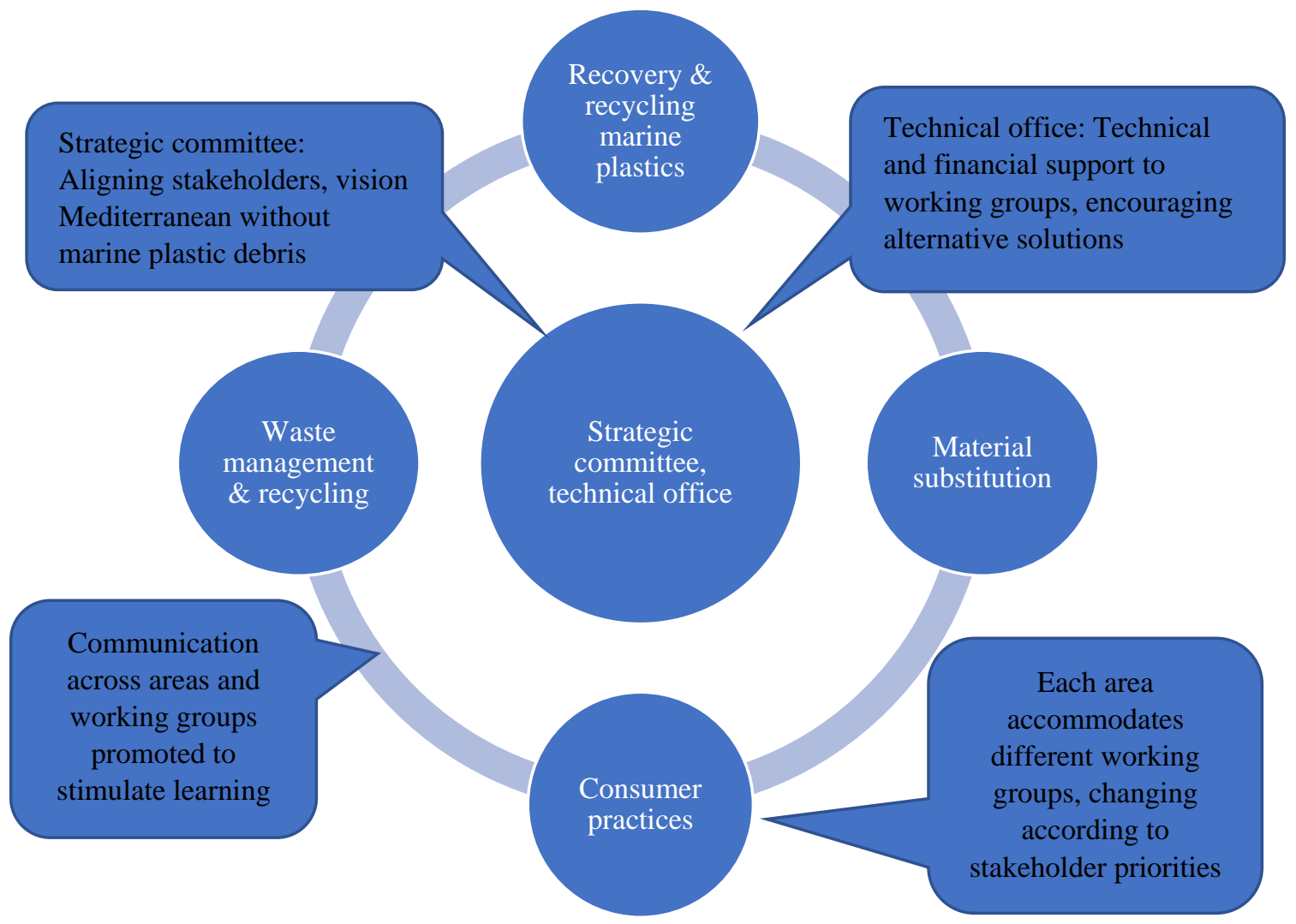

Source: Own elaboration, based on Fernández and Romagosa (2020) 


\section{References}

Ariño, X., \& Fernández, T. (2021). "Building responsible research and innovation ecosystems through shared agendas. The case of the B30 territory". Working Paper SeeRRI Project.

Boucher, J., \& Billard, G. (2020). The Mediterranean: Mare plasticum. Gland, Switzerland: IUCN.

EUMOFA. (2020). Blue bioeconomy. Situation report and perspectives 2020. Luxembourg: Publications Office of the European Union.

Fernández, T., \& Romagosa, M. (2020). "Articulating shared agendas for sustainability and social change" RIS3CAT Monitoring Collection, 8.

Fitjar, R. D., Benneworth, P., \& Asheim, B. T. (2019). "Towards regional responsible research and innovation? Integrating RRI and RIS3 in European innovation policy". Science and Public Policy, 46(5), 772-783.

Francocci, F., Paifelman, E., Ciappi, E., Aline, C., Corf, C. Le, Ruel, C., Efstratiou, C., Falini, G., Giannakourou, A., Solano-López, J. M., Strogyloudi, E., Raddadi, N., Valentini, S., \& Barbanti, A. (2019). MISTRAL Blue Growth Book. State of the art assessment and overview on the most relevant drivers and opportunities in the Mediterranean Blue Economy. MISTRAL project, Deliverable D3.1.2.

Marinelli, E., Fernández, T., \& Pontikakis, D. (2021). "Towards a transformative smart specialisation strategy: Lessons from Catalonia, Bulgaria and Greece". Publications Office of the European Union, Luxembourg.

Mazzucato, M. (2016). "From market fixing to market-creating: a new framework for innovation policy". Industry and Innovation, 23(2), 140-156.

Mendenhall, E. (2018). "Oceans of plastic: A research agenda to propel policy development". Marine Policy, 96(April), 291-298.

Miedzinski, M., Mazzucato, M., \& Ekins, P. (2019). “A framework for mission-oriented innovation policy roadmapping for the SDGs: The case of plastic-free oceans". UCL Institute for Innovation and Public Purpose, Working Paper Series 2019-03.

Molas-Gallart, J., Boni, A., Schot, J., \& Giachi, S. (2020). "A formative approach to the evaluation of transformative innovation policy". TIPC Working Paper 2020-01.

Schot, J., \& Steinmueller, W. E. (2018). "Three frames for innovation policy: R\&D, systems of innovation and transformative change". Research Policy, 47(9), 1554-1567.

Wayman, C., \& Niemann, H. (2021). "The fate of plastic in the ocean environment-a minireview". Environmental Science: Processes and Impacts, 23(2), 198-212. 